\title{
Tannin-phenol Formaldehyde Resins as Binders for Cellulosic Fibers: Mechanical Properties
}

\author{
A. S. Hussein ${ }^{1 *}$, K. I. Ibrahim ${ }^{1}$, K. M. Abdulla ${ }^{2}$ \\ Polymer Research Center, University of Basrah; State Company for Petrochemical Industries, Basrah , Iraq. \\ E-mail: hussanqi@yahoo.com
}

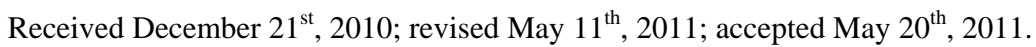

\begin{abstract}
In this study Eucalyptus tannin (T) was isolated from outer bark of Eucalyptus trees; as sodium phenoxide salt and used as extender or copolymer into phenol formaldehyde (PF) resin at five percent (10, 20, 30, 40 and 50)\% W/W. Tannin-phenol formaldehyde (TPF) and tannin formaldehyde-phenol formaldehyde (TFPF) resins that synthesized in this study were evaluated as adhesive material for cellulosic fibers by study the mechanical properties of the composite sheets. The results show that the substituting of $(P F)$ with tannin at (10-50)\% W/W give resins with mechanical properties comparable or near to those of pure $(P F)$, where the tensile strength at break $\left(T_{b}\right)$ ranging from $15.15 \mathrm{Mpa}$ to 22.27 Mpa as compared with 17.6 Mpa for pure (PF); while the impact strength properties (Im) of composites sheets increased with increased the (T) percents which were about $5.16 \mathrm{KJ} / \mathrm{m}^{2}$ for $(T P F-10 \%)$ and $7.21 \mathrm{KJ} / \mathrm{m}^{2}$ for (TPF-50\%) .On the other hand modification of $(T)$ to tannin formaldehyde resin (TF) appear less performance at the results of this study, this effect probably to low penetration of (TFPF) resins between the small voids of cellulose fibers when soaked it in resin solutions. In general the results of this study indicate that the Eucalyptus tannin can be used for partial substitution of (PF) to produce resins with feasible mechanical properties and can be used in some applications of $(P F)$ resins.
\end{abstract}

Keywords: Tannin, Tannin-formaldehyde Resins, Phenol-formaldehyde Resins, Mechanical Properties

\section{Introduction}

Tannins are one of the natural products which are widely distributed in plant kingdom, they are composed of different phenolic compounds [1,2]. Tannins are generally classified into two major types: hydrolysable tannins and condensed tannins, the hydrolysable tannins are mixture of simple phenols and it has had medicinal and cottage applications. Condensed tannins are polymeric phenolic compounds comprising from flavon-3-ol repeating units; Condensed tannins are known for their wide distribution in various softwood and hardwood, and it constitute about $90 \%$ of the total world production of commercial tannins [3].

Many studies show that the phenolic natural of tannin make it suitable for synthesis polymeric resins and adhesives; Hergert [4] stated that (30-50)\% W/W tannin replacement of the amino and phenolic resins have been formulated into wood adhesives. Saayman [5] reported tannin (Wattle tannin) utility in PF resins for wood adhesives requiring up to $30 \%$ of $\mathrm{PF}$ fortification to obtain a fully water-resistant bond. Other studies deal with reac- tion of tannin (Wattle tannin) with formaldehyde to synthesis polymeric resins $[6,7]$.

The purpose of this study was to evaluate the performance of Eucalyptus tannin as tannin sodium salt (T) or as tannin-formaldehyde resin (TF) into PF as binders for cellulosic fibers to produce composites sheets by study their mechanical properties.

\section{Experimental}

\subsection{Materials:}

Tannin was isolated from the outer bark of Eucalyptus tree, and used as crude without farther purification. Cellulose fibers (pulp) were used as sheets from National Company of Papers Industries, other chemicals used in this study were:

Sodium hydroxide and phosphoric acid from Fluka Chemical Company Inc.; phenol, ethanol and formalin solution (37-41)\% W/V from (H\&W).

\subsection{Instruments:}

The tensile properties were measured by using tensile 
strength instrument (Instron model 1193), and the impact strength was measured by impact testing instrument (Universal Pendulums model 6546/000), with 2J pendulum energy.

The composite sheets that prepared from these resins that synthesized in this study with cellulose fibers were cut into tensile test specimens (Dumbbell shape) and into impact test specimens by dumbbell cutter (Automatic Hollow Dipunch, made by Ceast Company). The samples sheets were compression-molded using hydrolic press (F. \& R. AL-Haddad Co.).

Dimensions of the samples were measured by micrometer (Brown \& Shape micrometer); (TMT Notch cutter model 43-15-1) was used for notching the impact test specimens.

\subsection{Isolation of Tannin:}

The powder of Eucalyptus outer bark was refluxed with sodium hydroxide solution $2 \%$ for $24 \mathrm{hr}$., and then the miture allowed to cool and filtrated. Sodium tannin phenoxide was used as tannin without naturalized or farther purification, the yield of it is about $(48-50) \%$ per total solids used (bark and sodium hydroxide).

\subsection{Resins Synthesis:}

TF resin was synthesized adopting the following procedure: $10 \mathrm{~g}$ tannin was dissolved in $50 \mathrm{ml}$ water, the $\mathrm{PH}$ of solution was adjusted to (10-11) by added some drops from $10 \% \mathrm{NaOH}$ solution, the temperature of the soltion raised to $80^{\circ} \mathrm{C}$ with stirring for $75 \mathrm{~min}$. Afterwards the solution was allowed to cool to $60^{\circ} \mathrm{C}$, then $40 \mathrm{ml}$ from formalin solution was added, the temperature of the mixture was kept at $60^{\circ} \mathrm{C}$; the reaction time was about 3 hr.

Tannin resins that synthesized consist of tannin-phenol formaldehyde (TPF), and tannin formaldehyde-phenol formaldehyde (TFPF); at five percent from tannin in the final resin (10, 20, 30, 40 and 50)\% W/W.

$\mathrm{PF}$ resin was synthesized according to the procedure described in references 8 and 9; TPF resins were synthsized by mixing the solution of predetermined weight of tannin with the mount of PF that give required proportion.

TFPF resins at (10, 20, 30, 40 and 50)\% from tannin were prepared by allowed the some method of TPF synthesis.

\subsection{Production of Composite Boards:}

The composite boards were prepared by soaking the cellulose fibers in $20 \% \mathrm{~W} / \mathrm{V}$ of resin solutions for $24 \mathrm{hr}$., then dried at room temperature and cut into test specimens. Test samples compressed under 150 psi pressure, at $(160-170)^{\circ} \mathrm{C}$ for $10 \mathrm{~min}$. The impact test samples had dimensions of ( $1 \mathrm{~cm}$ width, $0.2-0.17 \mathrm{~cm}$ thickness and 5 cm length). While the tensile test samples had $11.5 \mathrm{~cm}$ length, (0.2-0.17) cm thickness and $0.6 \mathrm{~cm}$ width.

\section{Measurements:}

The tensile properties were measured at across head speed $50 \mathrm{~mm} / \mathrm{min}$. and recorder speed $10 \mathrm{~mm} / \mathrm{min}$.; five samples were made for each test, the tensile strength tests carried out at $25^{\circ} \mathrm{C}$ and according to the ASTMD638-72(1986)[10a]. While the impact resistance acording to ASTM D256-56(1986)[10b].

\section{Results and Discussion}

Many study focused to reduced the cost of phenolic resins and to reduced their toxicity on humans and on the environment; some of this are used lignin and it's derivatives [12-14], another tries about using of tannins or other natural products $[15,16]$.

In this study the effects of Eucalpytus tannin and it's methylol derivative on the adhesion properties of PF for cellulose fibers was examined and evaluate the performance of these resins which contain tannin (T) or tannin formaldehyde (TF) as binders resins by study the mechanical properties of final composites sheets that made by it after thermal curing under press. The tensile properties of materials evaluated the rigidity, cross-linking, and flexibility of it. However the tensile strength of these composites (resins) showed in Figure 1 and Figure 2; it indicate that the tensile of the samples made by (10-30)\% tannin or tannin formaldehyde decrease relative to that of the sample which made by pure PF resin, where the tensile of the resins that contain tannin or tannin formaldehyde at all percent lower than of the pure PF except the resins that contain (40-50)\% W/W tannin have tensile values higher than that of PF.

This behavior mean that tannin or tannin formaldhyde resin decreased the amount of resins that act as binder because tannin not contain reactive functional groups can bonded in the network of resin matrix, on the other hand

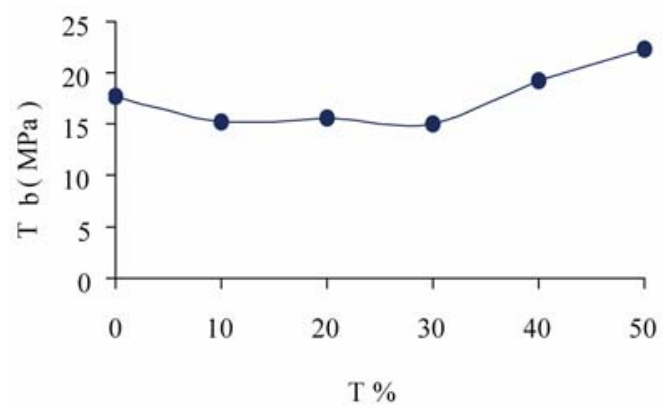

Figure 1. Tensile strength of TPF resins-cellulose fibers composite at different percent of tannin. 


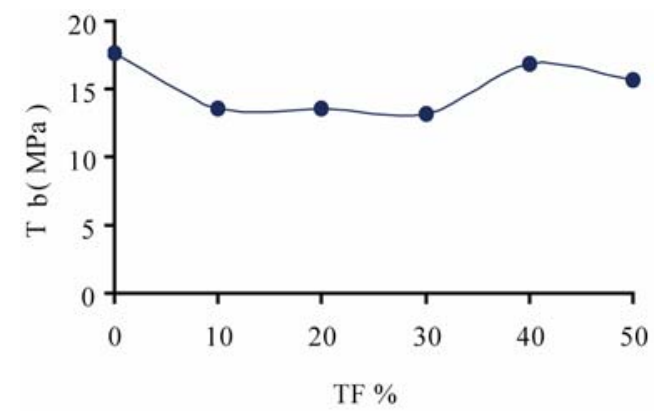

Figure 2. Tensile strength of TFPF resins-cellulose fibers composite at different percent tannin formaldehyde.

no significant effect to methylol groups of TF; Figure 2. this may be result to some factors of TFPF resin solutions or to method of cellulose fibers-resins samples preparation. The results showed in Figure 1 and $\mathbf{2}$ indicate that the tensile strength of the samples not continue in decreasing at percent of $10 \%, 20 \%$ and $30 \%$ from $\mathrm{T}$ or TF which about (15.15-15.01) Mpa and (13.6-13.1) Mpa respectively; in spite of reduce the amount of PF portion; there are some effects for $\mathrm{T}$ or TF in the final properties of the composites these effects may come from action of tannin as fillers which generally increase the rigidity of the samples or by act as extender with limit activity for tannin ability to form methylol groups when react with formaldehyde during hot press then can participate with $\mathrm{PF}$ in the formation of network resins but at little functional groups [17]; and the high density of polar functional groups in tannin lead to this behavior.

On the other hand, the impact strength of TPF resins treated cellulose fibers (Figure 4 and 5) at $\mathrm{T}$ percent $10 \%$ and $20 \%$ were lower than that of pure PF.

While the resins of $30 \%, 40 \%$ and $50 \%$ TPF gave an impact strength equal to that of pure PF about $7.2 \mathrm{KJ} / \mathrm{m}^{2}$, this brittleness appears to be the result to the action of tannin as fillers and also for behave of it as across-linking agent for substituted the lower levels of PF that needed to obtained similar mechanical properties. As can see the modification of $\mathrm{T}$ to $\mathrm{TF}$ did not improved the

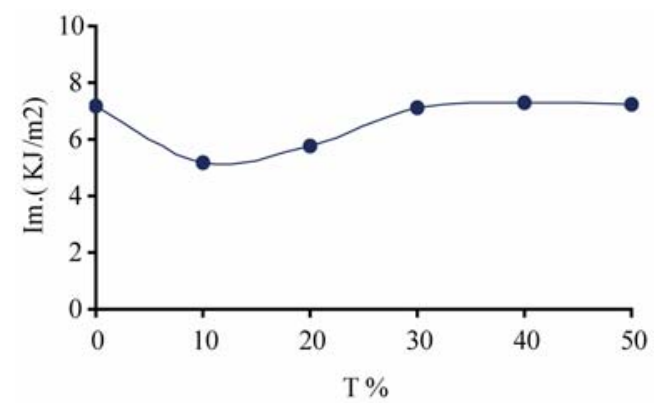

Figure 4. Impact strength of TPF resins-cellulose fibers composites.

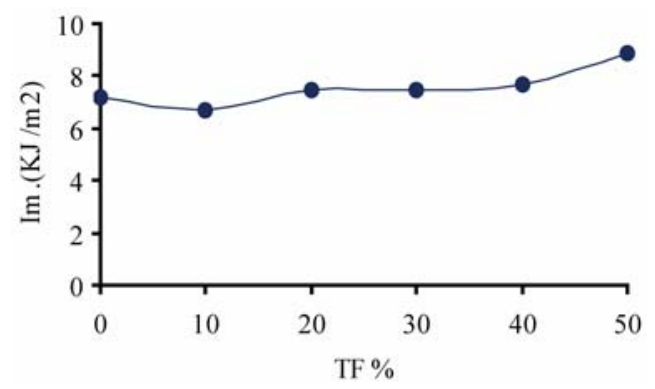

Figure 5. Impact strength of TFPF resins-cellulose fibers composites.

adhesion properties of these resins (Figure 5); the observed impact strength values of most composites that contain TF were generally higher than this contain $100 \%$ $\mathrm{PF}$, only one resin (TFPF-10\%) have impact value less than others; this flexibility appear to be the result to low diffusion of resins between the fibers. Therefore replace the soaking method by mixing the resins with fibers mechanically is expected to give samples with better mechanical and adhesion properties due to facilitate the diffusion and penetration of resins.

\section{Conclusions}

Used Eucalyptus tannin as tannin sodium salt into PF resin at $(10,20,30,40$ and 50)\% W/W can produce cellulose fibers-TPF composite sheets with mechanical properties comparable to that made with pure PF. The composed sheets produced by used tannin-formaldehyde resin into PF resin show lower satisfactory results. At the limited mechanical properties of this study; the used of Eucalyptus tannin as TPF or TFPF resins appear to be practically to reduced the ratio of PF in some of it's applications, Tannin act as filler or extender to participate in the formation adhesive bonds but at lower level and stiffness.

\section{REFERENCES}

[1] M. Belgacem and A. Gandini, "Monomers, Polymers and Composites from Renewable Resources," Elsevier Ltd. Cambridge, 2008, PP. 179-200.

[2] J. M. Chesworth, T. Stuchbury and J. R. Scaif, “An Introduction to Agricultural Biochemistry,” Chapman and Hall, London, 1998, pp. 55-58.

[3] J. M. Garro Galvez, B. Riedl and A. H. Conner, "Analytical Studies on Tara Tannins,” Holzforschung, Vol. 51, No. 3, 1997, pp. 235-243.doi:10.1515/hfsg.1997.51.3.235

[4] R. W. Hemingway and A. H. Conner (eds), "Adhesives from Renewable Resource,” ACS symposium series 285, Am. Chem. Soc., Washington, 1989, pp. 155-171.

[5] H. M. Saayman and J. A. Qatly, "Wood Adhesives from Wattle Bark Extract," Proceeding of the conference on wood gluing. International Union of Forestry Research 
Organization, Madison, 22-23 September 1975, pp. 28-45.

[6] S. Kim and H. -J. Kim, "Evaluation of Formaldehyde Emission of Pine and Wattle Tannin-Based Adhesives by Gas Chromatography,” Holz Roh Werkst, Vol. 62, No. 2, 2004, pp. 101-106. doi:10.1515/hfsg.1997.51.3.235

[7] M. T. Paridah and O. C. Musgrave, "Alkline Treatment of Sulfited Tannin-Based Adhesive from Mangrove to Increase Bond Integrity of Beech Slips,” Journal of Tropical Forest Science, Vol. 18, 2006, pp. 137-143.

[8] G. A. Adam, "Chemistry and Technology of Methylolic Resins: Their Derivatives and IPNs,” National journal of Chemistry, Vol. 1, 2001, pp. 131-157.

[9] A. K. Raheem, "Synthesis, Characterization and Study of Some New Epoxy Resins and Resinous Amines as Hardners,” Ph.D. Thesis, University of Basrah, Basrah, 1992.

[10] A-Annual book of ASTM Standard, "Tensile Properties of Plastics,” Vol. 8.1, 1986, D638-84. B-Annual book of ASTM Standard, "Standard Test Methods for Impact Resistance of Plastics and Electrical Insulating Materials,” Vol. 8.1, 1986, D256-84.
[11] M. Olivares, H. Aceituno, G. Neiman, E. Rivera and T. Sellers, "Ligin-Modified Phenolic Adhesives for Bonding Radiata Pine Plywood,” Forest product Journal, vol. 45, No. 1, 1995, pp. 63-67.

[12] T. Sellers, "Survey Reveals Use of Lignin as Partial Substitute for Phenol," Panel World, Vol. 31, 1990, pp. 26-29.

[13] R. W. Hemingway, A. H. Conner and S. J. Branham, "Adhesives from Renewable Resources," ACS Symposium, Washington, 1989, pp. 13-42.

[14] A. Pizzi, "Advanceed Wood Adhesives Technology," Marcel Dekker, New York, 1994, pp. 149-217.

[15] M. D. Fabricio and A. R. L. Francisco, “Alternative Castor Oil-Based Polyurthane Adhesives Used in Production of Plywood," Materials Research, Vol. 7, No. 3, 2004, p. 413. doi:10.1590/S1516-14392004000300007

[16] D. J. Gardner, S. K. Waage and T. J. Elder, "Bonding Flakeboard with Filled and Extended Phenol-Formaldehyde Resin,” Forest Products Journal, Vol. 40, 1990, pp. 31-36. 